\title{
TEAM-BASED REHABILITATION AFTER TRAUMATIC BRAIN INJURY: A QUALITATIVE SYNTHESIS OF EVIDENCE OF EXPERIENCES OF THE REHABILITATION PROCESS
}

Maria LARSSON-LUND ${ }^{\circledR}$, OT, PhD $^{1}$, Agneta PETTERSSON ${ }^{\circledR 2}$, PhD and Thomas STRANDBERG ${ }^{\circledR 3,4}, \mathrm{SCW}^{2}, \mathrm{PhD}^{2}$

From the ${ }^{1}$ Department of Health, Education and Technology, Occupational Therapy, Lulea University of Technology, Lulea, ${ }^{2}$ Swedish Agency for Health Technology Assessment and Assessment of Social Services, SBU, Stockholm, ${ }^{3}$ School of Health and Welfare, Dalarna University, Falun and ${ }^{4}$ The Swedish Institute for Disability Research, Örebro University, Örebro, Sweden

Objective: To synthesize and explore experiences of the rehabilitation process for adults with traumatic brain injury receiving team-based rehabilitation. Data sources: A qualitative evidence synthesis was conducted according to the "Enhancing transparency in reporting the synthesis of qualitative research" (ENTREQ) Guidelines, of qualitative studies published in 5 databases in 2000-21.

Study selection and data extraction: Screening, selection of relevant studies, assessment of methodological limitations, systematic qualitative content analysis and assessment of confidence with Grading of Recommendations Assessment, Development, and Evaluation- Confidence in the Evidence from Reviews of Qualitative research (GRADE-CERQual) were carried out by independent researchers.

Data synthesis: The 10 included studies revealed how people with traumatic brain injury perceived that they struggled on their own for a long time to adapt their daily life. They experienced that access to team-based rehabilitation was scarce and that the interventions offered were neither individually tailored nor coordinated. A respectful attitude from professionals and individually adapted information facilitated their rehabilitation process.

Conclusion: This qualitative evidence synthesis indicates areas for improvement and a need to develop person-centred team-based rehabilitation for adults with traumatic brain injury, in terms of accessibility, coordination, continuity, content and participation. Given the limited opportunities for team-based rehabilitation after hospital discharge, further research is needed to understand how rehabilitation can support the adaptation of everyday life.

Key words: brain injury; evidence-based practice; rehabilitation; review; qualitative research; qualitative evidence synthesis.

Accepted Dec 21, 2021; Epub ahead of print Jan 12, 2022

J Rehabil Med 2022; 54: jrm00253

Correspondence address: Maria Larsson-Lund, Department of Health Science, Occupational Therapy, Luleå University of Technology, 97187 Luleå, Sweden. E-mail: maria.larsson-lund@ltu.se

$\mathrm{T}$ raumatic brain injury (TBI) affects millions of people worldwide of all ages $(1,2)$, and the outcome of the injury varies from complete recovery to life-long disability or death (3). TBI can be either severe, mo-

\section{LAY ABSTRACT}

The aim of this study was to review scientific publications about experiences of the rehabilitation process from the perspective of adults with traumatic brain injury who had received team-based rehabilitation. Several established databases were searched, yielding 10 relevant qualitative studies. The experiences described in these studies overlapped, and showed that people with traumatic brain injury struggled on their own over a long period of time to adapt to their new situation in everyday life. They experienced that access to team-based rehabilitation was limited and not adapted to their needs at different time-points. As many people with traumatic brain injury had limited experience of teambased rehabilitation after hospital discharge, this study indicates a need to develop person-centred team-based rehabilitation over a longer period of time. Further research is needed regarding experiences of how rehabilitation can support adaptation in everyday life after traumatic brain injury.

derate or mild (4), and many people need to undergo prolonged rehabilitation to adapt their daily life after injury, as they may have various long-term physical, cognitive, and psychosocial impairments $(5,6)$. Given the individual and multifaceted consequences, the rehabilitation process must be managed by a multiprofessional rehabilitation team throughout all phases (3, 7-9). Commonly, coordination also needs to take place between professionals and teams at different levels and organizations of care $(8,10)$. In addition, rehabilitation needs to be individualized, e.g. person-centred, due to the complexity of TBI (8). Consequently, multiprofessional team-based rehabilitation plays a crucial role in rehabilitation outcomes following TBI $(8,9$, 11). Systematic reviews show some evidence of the effects of specific and team-based rehabilitation after TBI (12-14). However, no qualitative evidence synthesis (QES) of people with TBI has addressed how adults receiving team-based rehabilitation experience the rehabilitation process. Existing QESs have focused on the experience of losses and recovery (15) and the experiences of rehabilitation approaches using music and poems (16). More comprehensive knowledge of the lived experiences of the rehabilitation process, from the perspective of people with TBI, is important 
in evaluating whether team-based rehabilitation meets their needs and expectations to inform improvements in rehabilitation.

The aim of this QES was to explore the experiences of the rehabilitation process for adults with TBI receiving multi-professional team-based rehabilitation, with a focus on the experiences of relationships with professionals, coordination between professionals in rehabilitation, and the importance of rehabilitation for daily life.

\section{METHODS}

This QES is part of a governmental health technology assessment of TBI rehabilitation commissioned by the Swedish agency for health technology assessment and assessment of social services (Statens bredning för medicinsk och social utvärdering (SBU)) (17) and includes an updated search using the same search strategy. The QES was conducted by 3 researchers according to the "Enhancing transparency in reporting the synthesis of qualitative research" (ENTREQ) Guidelines (18). The protocol for the full assessment of rehabilitation after TBI was registered with the International Prospective Register of Systematic Reviews (PROSPERO) (number CRD42018102822).

\section{Literature search and inclusion and exclusion criteria}

A literature search of the following databases was performed: PubMed, EMBASE, Cochrane Library, CINAHL and PsycInfo, from 2000 to 24 March 2021. The search was comprehensive, and a broad strategy, aimed at capturing studies on TBI and using qualitative methods, was applied. Studies addressing rehabilitation according to the selection criteria were identified in the screening. The full search strategy is published at SBU (17), and an exemplar search in 1 database is shown in Appendix 1.

Inclusion criteria were: qualitative studies based on individual interviews or focus groups with adults ( $>16$ years) with any severity of TBI concerning their experiences of the rehabilitation process after team-based rehabilitation. Only peer-reviewed articles in English and Scandinavian languages were included.

Exclusion criteria were: articles that only included experiences of rehabilitation of specific symptoms or experience of the adaptation process without specific reference to team-based rehabilitation. Studies of experiences of rehabilitation services provided by 1 profession were excluded. In addition, studies of rehabilitation that involved a specific component or a specific focus, such as music therapy, a technical solution, or vocational rehabilitation, were excluded. Studies that involved other types of brain injuries were excluded if those with TBI were approximately less than half of the sample, or if their proportion of the sample was unclear. Studies that involved both participants with TBI and others were excluded if it was unclear which the results were based on.

\section{Selection of studies}

Titles and abstracts were screened based on the inclusion and exclusion criteria by 2 independent researchers to identify relevant abstracts. Thereafter, 2 researchers (MLL, TS) read these abstracts independently, and potentially relevant studies were read in full text. The researchers made an individual assessment of whether the studies fulfilled the criteria and then made a final decision in consensus. The risk that the study findings were affected by limitations in the design and conduct of the study was assessed in a quality appraisal, based on a review protocol available at SBU (Appendix 2). This assessment was first performed independently by the researchers and thereafter discussed jointly before a final decision was made in consensus. Only studies with minor or moderate levels of limitations were included. The selection process is shown in Fig. 1. The excluded studies and reasons for exclusion are listed in Appendix 3.

\section{Qualitative evidence synthesis}

Systematic qualitative content analysis (19) was chosen to inductively analyse and synthesize the content of findings across the studies. The method is a knowledge-building qualitative systematic review that generates new evidence based on multiple qualitative studies to support evidence-based practice. Two researchers (MLL, TS) worked independently with each step of the QES, followed by a discussion and consensus. First, the texts were read to gain an understanding of the whole. Data segments with content relevant to the aim were extracted from the results sections of the studies. The segments were transferred to a matrix and were assigned preliminary codes close to the text. The codes were combined with reflective notes to preserve the understanding of the data. Thereafter, codes and notes were synthesized across studies. Because the studies focused on experiences from different phases of the rehabilitation process, the codes were sorted according to a time perspective, from the acute phases in hospital to post-acute rehabilitation at home, and the late phase ( $>6$ months after admission). Codes with similar contents were abstracted to preliminary categories, and these were later grouped into preliminary subcategories. The preliminary subcategories were then abstracted and refined to final categories with subcategories. An example of the synthesis process is shown in Table I.

The second researcher (AP) validated each step in the process. A reflective approach was adopted throughout to ensure the fit of the synthesis, meaning that the findings should be grounded in the data and inter-related to form a systematic whole (19).

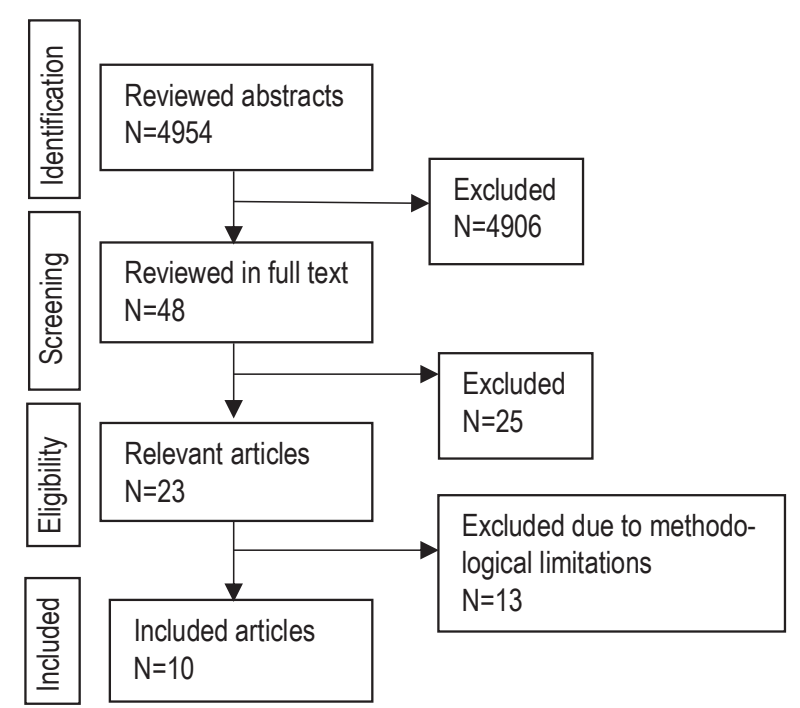

Fig. 1. Flow chart for selection of studies. 
Table I. An example of the qualitative evidence synthesis (QES)

\begin{tabular}{|c|c|c|c|}
\hline Data segment & Code & Subcategory & Category \\
\hline $\begin{array}{l}\text { The practical organization of rehabilitation after returning home } \\
\text { was described as deficient. A participant with a moderate traumatic } \\
\text { brain injury described how poorly organized rehabilitation impeded } \\
\text { reintegration to practical and social daily life: }\end{array}$ & $\begin{array}{l}\text { Lack of coordinated } \\
\text { support influence } \\
\text { reintegration } \\
\text { negatively }\end{array}$ & \multirow{2}{*}{$\begin{array}{l}\text { Being in a gap of insufficient } \\
\text { coordination of rehabilitation } \\
\text { between the hospital and } \\
\text { continued actions during the } \\
\text { transition }\end{array}$} & \multirow[t]{2}{*}{$\begin{array}{l}\text { Finding hospital rehabilitation } \\
\text { to be poorly organized, with } \\
\text { insufficient support and } \\
\text { participation }\end{array}$} \\
\hline $\begin{array}{l}\text { "I have been missing some information and notice about what is going } \\
\text { to happen and when. Because very often things happen simultaneously, } \\
\text { and that is very frustrating when you have a traumatic brain injury." }\end{array}$ & & & \\
\hline
\end{tabular}

\section{Confidence in the findings}

The confidence in each of the subcategory findings was assessed with Grading of Recommendations Assessment, Development, and Evaluation- Confidence in the Evidence from Reviews of Qualitative research (GRADE-CERQual) (20-22) by joint discussions between the authors. The discussion was based on consensus regarding the quality appraisal of the items in Appendix 2 for each of the included articles (i.e. the specific articles that built up a subcategory). Confidence in each subcategory was assessed separately by the 4 domains (in the GRADECERQual framework): methodological limitations, relevance of the data, coherence and adequacy of data. The confidence was categorized into 4 levels: high, moderate, low, and very low.

\section{RESULTS}

The search retrieved 10 studies that met the inclusion criteria. (Table II): 6 from Australia (23-28), 2 from the UK $(29,30)$, and 2 from Scandinavia $(31,32)$. The studies included a total of 138 persons, of whom 52 were women. Each study included between 6 and 20 persons. Participants were mostly of working age $(<65$ years), and 3 studies $(24,29,30)$ included participants over 65 years. The time since injury varied between one month and 6 years in most of the studies. A majority of the participants had moderate or severe TBI.

The synthesis formed 3 categories:

- Struggling with adapting to life with new conditions;

- Facing limited access to individually tailored and coordinated team-based rehabilitation over time; and

- Interacting with rehabilitation personnel and close persons influenced the rehabilitation process.

These 3 categories each consisted of 3-4 subcategories (Table III).

The participants' experiences of the rehabilitation process showed that they went through an "inner"

Table II. Included studies

\begin{tabular}{|c|c|c|c|c|c|}
\hline Reference & Aim & Setting & Participants & Data collection & $\begin{array}{l}\text { Data } \\
\text { analysis }\end{array}$ \\
\hline $\begin{array}{l}\text { Abrahamson et al. } \\
(64), 2017\end{array}$ & $\begin{array}{l}\text { Explore experiences from the transition from } \\
\text { in-patient rehabilitation to the community }\end{array}$ & $\begin{array}{l}\text { Specialist inpatient } \\
\text { neurorehabilitation unit in an } \\
\text { NHS teaching hospital. } \\
\text { UK }\end{array}$ & $\begin{array}{l}\text { Adults with severe TBI } \\
\text { Age range } 48-89 \text { years } \\
n=10\end{array}$ & $\begin{array}{l}\text { Interview and field } \\
\text { notes }\end{array}$ & $\begin{array}{l}\text { Thematic } \\
\text { analysis, } \\
\text { data driven }\end{array}$ \\
\hline $\begin{array}{l}\text { Copley et al. (65), } \\
2013\end{array}$ & $\begin{array}{l}\text { Describe experiences of care and the factors } \\
\text { that impacted upon participants' ability to } \\
\text { access services }\end{array}$ & $\begin{array}{l}\text { Former patients at } 2 \\
\text { metropolitan acute trauma } \\
\text { hospitals. } \\
\text { Australia }\end{array}$ & $\begin{array}{l}\text { Adults with moderate to } \\
\text { severe TBI } \\
\text { Age range } 18-65 \text { years } \\
n=14\end{array}$ & $\begin{array}{l}\text { Interviews and guided } \\
\text { oral history }\end{array}$ & $\begin{array}{l}\text { Thematic } \\
\text { analysis }\end{array}$ \\
\hline $\begin{array}{l}\text { D'Cruz et al. (66), } \\
2016\end{array}$ & $\begin{array}{l}\text { Explore the client perspectives of client- } \\
\text { centred occupational therapy }\end{array}$ & $\begin{array}{l}\text { One occupational therapy } \\
\text { practice in metropolitan area. } \\
\text { Australia }\end{array}$ & $\begin{array}{l}\text { Adults with moderate to } \\
\text { severe TBI } \\
\text { Age range } 20-71 \text { years } \\
n=6\end{array}$ & $\begin{array}{l}\text { Semi-structured } \\
\text { interviews. Memos } \\
\text { and reflective journals }\end{array}$ & $\begin{array}{l}\text { Constant } \\
\text { comparison }\end{array}$ \\
\hline $\begin{array}{l}\text { Fleming et al. (67), } \\
2012\end{array}$ & $\begin{array}{l}\text { Describe the in-patient rehabilitation } \\
\text { experiences prior to discharge }\end{array}$ & $\begin{array}{l}\text { One rehabilitation unit at a } \\
\text { large metropolitan hospital. } \\
\text { Australia }\end{array}$ & $\begin{array}{l}\text { Adults with TBI/ABI } \\
\text { Age range } 24-65 \text { years } \\
n=20\end{array}$ & In-depth interviews & $\begin{array}{l}\text { Manifest } \\
\text { content } \\
\text { analysis }\end{array}$ \\
\hline $\begin{array}{l}\text { Graff et al. (68), } \\
2018\end{array}$ & $\begin{array}{l}\text { Explore the living experience from hospital } \\
\text { discharge up to } 4 \text { years post-injury }\end{array}$ & $\begin{array}{l}\text { The trauma centre for } \\
\text { severely injured patients at a } \\
\text { university hospital. } \\
\text { Denmark }\end{array}$ & $\begin{array}{l}\text { Adults with TBI } \\
\text { Age range } 25-63 \text { years } \\
n=20\end{array}$ & $\begin{array}{l}\text { In-depth interviews } \\
\text { and field notes }\end{array}$ & $\begin{array}{l}\text { Thematic } \\
\text { analysis }\end{array}$ \\
\hline $\begin{array}{l}\text { Lexell et al. (69), } \\
2013\end{array}$ & $\begin{array}{l}\text { Describe the experiences of an outpatient } \\
\text { group rehabilitation programme }\end{array}$ & $\begin{array}{l}\text { Community. } \\
\text { Sweden }\end{array}$ & $\begin{array}{l}\text { Adults with TBI/ABI } \\
\text { Age range } 25-62 \text { years } \\
n=11\end{array}$ & $\begin{array}{l}\text { Semi-structured } \\
\text { interviews }\end{array}$ & $\begin{array}{l}\text { Qualitative } \\
\text { content } \\
\text { analysis }\end{array}$ \\
\hline $\begin{array}{l}\text { Mueller et al. (70), } \\
2017\end{array}$ & $\begin{array}{l}\text { Explore how medical and social services } \\
\text { support community-based patients }\end{array}$ & $\begin{array}{l}\text { A newly established pilot } \\
\text { clinical service for TBI. } \\
\text { UK }\end{array}$ & $\begin{array}{l}\text { Adults with TBI } \\
\text { Age } 18 \text { years and above } \\
n=10\end{array}$ & $\begin{array}{l}\text { Semi-structured } \\
\text { interviews and field } \\
\text { notes }\end{array}$ & $\begin{array}{l}\text { Thematic } \\
\text { analysis }\end{array}$ \\
\hline $\begin{array}{l}\text { O'Callaghan et al. } \\
(71), 2012\end{array}$ & $\begin{array}{l}\text { Explore experiences of healthcare of adults } \\
\text { with moderate to severe TBI }\end{array}$ & $\begin{array}{l}\text { Community. } \\
\text { Australia }\end{array}$ & $\begin{array}{l}\text { Adults with TBI } \\
\text { All age groups } \\
n=14\end{array}$ & $\begin{array}{l}\text { Unstructured } \\
\text { interviews based on } \\
\text { guided oral history }\end{array}$ & $\begin{array}{l}\text { Thematic } \\
\text { analysis }\end{array}$ \\
\hline $\begin{array}{l}\text { Turner et al. (72), } \\
2007\end{array}$ & $\begin{array}{l}\text { Explore the lived transition experiences of } \\
\text { individuals with } A B I \text { and their caregivers }\end{array}$ & $\begin{array}{l}\text { One outpatient and } 1 \text { case } \\
\text { management service. } \\
\text { Australia }\end{array}$ & $\begin{array}{l}\text { Adults with TBI } \\
\text { Age range } 19-53 \text { years } \\
n=13\end{array}$ & $\begin{array}{l}\text { Semi-structured } \\
\text { interviews }\end{array}$ & $\begin{array}{l}\text { Qualitative } \\
\text { content } \\
\text { analysis }\end{array}$ \\
\hline $\begin{array}{l}\text { Turner et al. (73), } \\
2011\end{array}$ & $\begin{array}{l}\text { Study the experience during the transition } \\
\text { phase from hospital to home and the } \\
\text { perceived factors influencing the service and } \\
\text { support needs during the transition phase }\end{array}$ & $\begin{array}{l}\text { One metropolitan- based in- } \\
\text { patient rehabilitation unit. } \\
\text { Australia }\end{array}$ & $\begin{array}{l}\text { Adults with } \mathrm{ABI} / \mathrm{TBI} \\
\text { Age range } 17-63 \text { years } \\
n=20\end{array}$ & $\begin{array}{l}\text { Semi-structured } \\
\text { interviews }\end{array}$ & $\begin{array}{l}\text { Thematic } \\
\text { analysis }\end{array}$ \\
\hline
\end{tabular}

$\mathrm{ABI}$ : acquired brain injury; TBI: traumatic brain injury. 
Table III. Findings from the qualitative evidence synthesis (QES) of experiences of the rehabilitation process in persons with traumatic brain injury (TBI), based on 10 qualitative studies, and the confidence of the results expressed according to GRADE-CERQual

\begin{tabular}{|c|c|c|c|}
\hline Category & Subcategory & $\begin{array}{l}\text { No. of studies (no. of study } \\
\text { participants) that the } \\
\text { subcategory was based on }\end{array}$ & $\begin{array}{l}\text { Confidence of the } \\
\text { subcategory according } \\
\text { to CERQual }\end{array}$ \\
\hline \multirow[t]{3}{*}{$\begin{array}{l}\text { Struggling with adapting to a life on } \\
\text { new conditions }\end{array}$} & $\begin{array}{l}\text { Becoming aware of the injury and being emotionally } \\
\text { vulnerable during the hospital stay. }\end{array}$ & $3(43)$ & Low $^{a}$ \\
\hline & $\begin{array}{l}\text { Being challenged with an increased understanding of the } \\
\text { long-term consequences on everyday life following the } \\
\text { transition to the home }\end{array}$ & $5(77)$ & Moderate $^{b}$ \\
\hline & $\begin{array}{l}\text { Struggling on one's own to adapt to daily life after formal } \\
\text { rehabilitation had ceased }\end{array}$ & $6(88)$ & Moderate $^{b}$ \\
\hline \multirow{4}{*}{$\begin{array}{l}\text { Facing limited access to individually } \\
\text { tailored and coordinated team- based } \\
\text { rehabilitation }\end{array}$} & $\begin{array}{l}\text { Finding hospital rehabilitation to be poorly organized, with } \\
\text { insufficient support and participation. }\end{array}$ & $4(63)$ & Low $^{a}$ \\
\hline & $\begin{array}{l}\text { Being stuck in a gap of insufficient coordination of } \\
\text { rehabilitation between the hospital and home }\end{array}$ & $5(67)$ & Low $^{a}$ \\
\hline & $\begin{array}{l}\text { Experiencing limited access to a rehabilitation supporting } \\
\text { reintegration into society evoked feelings of powerlessness }\end{array}$ & $6(71)$ & Moderate $^{b}$ \\
\hline & $\begin{array}{l}\text { Engaging in individually tailored rehabilitation over time was } \\
\text { crucial for the adaptation process }\end{array}$ & $3(30)$ & Very low ${ }^{c}$ \\
\hline \multirow{3}{*}{$\begin{array}{l}\text { Interacting with rehabilitation } \\
\text { personnel and close persons } \\
\text { influenced the rehabilitation process }\end{array}$} & $\begin{array}{l}\text { The way one was treated influenced whether the } \\
\text { rehabilitation was experienced as person-centred }\end{array}$ & $4(51)$ & Low $^{a}$ \\
\hline & $\begin{array}{l}\text { Impersonal and scant information on the course of } \\
\text { rehabilitation and future possibilities were experienced as an } \\
\text { obstacle in the rehabilitation process }\end{array}$ & $4(55)$ & Low $^{a}$ \\
\hline & $\begin{array}{l}\text { The involvement of close persons was crucial for the } \\
\text { rehabilitation process }\end{array}$ & $7(121)$ & Moderate $^{b}$ \\
\hline
\end{tabular}

${ }^{a}$ Very serious uncertainty in Data adequacy $(-2)$ due to few studies and few participants. ${ }^{b}$ Serious uncertainty in Data adequacy $(-1)$ due to relatively few studies and participants. 'Very serious uncertainty in Data adequacy $(-2)$ due to few studies and few participants, and serious uncertainty in Relevance ( 1$)$ as participants had other types of ABI than TBI. GRADE-CERQual: Hidradenitis Suppurativa International Online Community: Patient Characteristics and a Novel Model of Treatment Effectiveness

struggle (first category) that was integrated and parallel to their experiences of formal team-based rehabilitation (second and third categories).

\section{Struggling with adapting to life with new conditions}

Participants experienced the rehabilitation to be a demanding process of adapting to a new life with new conditions, characterized by an inner struggle, ranging from onset of the injury to several years later (25-31). Becoming aware of the injury and being emotionally vulnerable during the hospital stay. Rehabilitation at the hospital was initially associated with an overwhelming experience when participants became aware of their brain injury $(25,27,30)$. When their condition stabilized, they slowly realized that many functions were affected, such as balance, coordination, vision, and memory, and they experienced extensive fatigue $(27,30)$. As they experienced a loss of activities of daily life, different emotions arose, such as frustration, sadness, and worries:

"What I find more frustrating than anything, is, at this present moment in time, I cannot do what I want to do and what I used to be able to do" (30) (p. 1689).

Being challenged with an increased understanding of the long-term consequences on everyday life following transition to the home. After the transition from hospital to home, previously unknown consequences of TBI in everyday life became evident for the participants $(26-28,30,31)$. They had expected that everyday life would return to normal, but life became everything else but normal $(27,30,31)$. The transition was described as overwhelming, as the participants became aware of changes that they had not realized before (26-28, 30, 31):

"Yeah, when you come home it is a bit of a shock because all of a sudden you're at home and like I say, I found it hard because I couldn't do all the things that I used to do and that's what upset me. I wasn 't prepared for how much shock I got." (27) (p. 1124).

Struggling on one's own to adapt to daily life after formal rehabilitation had ceased. After the rehabilitation had ceased, an even more vulnerable life situation than before the transition from hospital was experienced $(26-29,31)$. The participants had to continue with the adaptation without professional support. In this process, they re-evaluated their life and realized the importance of finding new goals and meaning in their changed life situation $(26-29,31)$. This was experienced as a traumatic process, including grieving the loss of their former self to be able to accept the new self (26). They struggled with their changed abilities in daily life $(26,31)$, finding it difficult to perform activities and uphold routines (27). Some of the participants were worried about the future (31). Meaningful activities and hobbies were important, as they gave meaning to life (27), as illustrated:

"It gives me a bit of passion back. I thrive in that environment, I really do." (27) (p. 1125).

\section{Facing limited access to individually tailored and co- ordinated team-based rehabilitation}

The participants in all studies described insufficient access to team-based rehabilitation, especially to reha- 
bilitation that was individually tailored and coordinated during all phases of the recovery (23-32).

Finding hospital rehabilitation to be poorly organized, with insufficient support and participation. The experiences of rehabilitation at the hospital were mixed (25, $27,28,30)$. The participants considered that medical treatment and rehabilitation were of high quality $(25$, $27)$, although the rehabilitation was not as intense as expected $(25,27,28)$. Other participants experienced that they did not receive the support they needed and that their participation in the planning of their rehabilitation was restricted. The rehabilitation was seen as disorganized when it was delayed (30) or when there was a lack of coordination between $\operatorname{staff}(25,30)$ :

'You'd ask someone one thing and you might not see them again. And they wouldn't tell me anything that was going on. They wouldn't answer my questions, you know?" (30) (p. 1688).

Aside from the rehabilitation sessions, the participants were referred to few activities on the ward $(25,30)$. This experience evoked feelings of meaninglessness or boredom, with participants seeking opportunities to use their time in a more purposeful way.

Being stuck in a gap of insufficient coordination of rehabilitation between the hospital and home. The preparation, planning and coordination of rehabilitation and other support both before and during the transition to the home were experienced as insufficient (26-28, 30, 31). Upon reflection, participants wished that they were better prepared for going home and that the planning of the continued rehabilitation had been more clearly outlined $(26-28,30,31)$ :

"Nobody prepared me for home... Nobody said, 'Well, what are you going to do when you get there?... I just needed a bit more guidance on how it was going to be" (30) (p. 1688).

In the home, the participants often did not know who to contact when new needs arose $(27,30,31)$. The participants described that rehabilitation was delayed for weeks up to months and was provided less frequently than expected $(27,28,30)$. They felt that the rehabilitation had a short time perspective, while they wanted to focus on future long-term goals for reintegration in society, such as return to work and transport (30). Some participants experienced that they had only a few follow-ups after discharge (26) or that the services they received were not coordinated $(27,30)$. They also had unanswered questions about their medical condition and medical care (30). All these experiences led to feelings of being in a service gap and of being abandoned (26-28, 30, 31).

Experiencing limited access to rehabilitation supporting reintegration into society evoked feelings of powerlessness. In the later phase, when striving to reintegrate into society, the participants described that it was difficult to understand and find their way in the complex support system. This included all kinds of services. They described a continuous struggle to obtain access to rehabilitation $(23,26-29,31)$, including knowing whom to contact, what kinds of interventions were available and if they had the right to access them $(23,27,28,30)$. They felt dependent on close persons or case managers to help them navigate the system and request support $(23,27,28,30)$. The participants experienced that their own initiatives were crucial to obtaining access to services $(23,27,28,31)$. The lack of coordinated rehabilitation and other forms of services evoked feelings of powerlessness, frustration and abandonment $(23,26-29,31)$. A common view was that the rehabilitation was more effective and resulted in better outcomes when individually tailored and coordinated services were given at the right time:

"I think they should focus on the best rehabilitation plan to optimize the patient's potential, this is my only complaint. They have offered me rehabilitation in a gym on an exercise bike, which can be great for some people, but not for a young person with a traumatic brain injury. I want a good life later, and I have more cognitive problems than physical. Then, it's not enough" (31) (p. 931).

Engaging in individually tailored rehabilitation over time was crucial for the adaptation process. The participants emphasized that it was important that the rehabilitation was tailored to individual needs that varied over time (23-32). However, only 1 of the included studies had investigated the actual experiences of rehabilitation programmes in depth (32), and 2 other studies to some extent covered experiences of actually having received rehabilitation $(24,26)$. The participants stressed that the rehabilitation should support adaptation of activities of daily life, roles and identity $(24,26,32)$ :

"I have benefitted a lot from this [group rehabilitation], it has been absolutely crucial [to come here]. If you don't get the help you need, it can get really difficult... without the group rehabilitation I doubt that I had managed it by myself." (32) (p.534).

An essential part of the rehabilitation, according to the participants, was to facilitate an acceptance that life was different from before but could be good anyway $(24,26,32)$. As the adaptation process took place over a longer period time $(24,26,32)$, it was seen as essential to receive cohesive rehabilitation over time with recurrent follow-ups (32). The participants described that rehabilitation had been crucial to help them adapt and become more satisfied with their life (32). The adaptation was facilitated by learning strategies to solve problems in activities of daily life, including the use of assistive devices and the support of other persons. Strategies for managing changes in social relations and knowledge about TBI were also helpful in the adaptation process. 
Rehabilitation that enabled peer sharing with others in the same situation $(24,26,32)$ gave perspectives on their own situation and enabled the participants to identify new opportunities. The participants emphasized the importance of taking responsibility for their success with the rehabilitation $(24,26,32)$ by, between the rehabilitation sessions, processing and practising skills learned (32).

\section{Interacting with rehabilitation personnel and close persons influenced the rehabilitation process}

The participants' experiences showed the importance of relations and collaborations throughout the whole rehabilitation process $(23-25,27-32)$.

The way one was treated influenced whether the rehabilitation was experienced as person-centred. The participants described that their relationship with the professionals influenced to what degree rehabilitation was felt as person-centred $(24,25,30,32)$. They expressed the need to be seen as the person they were and not only as a patient $(24,25,30)$. A professional relationship combined with competences about the specific needs of persons with TBI was described as important for how they were treated as well as for the outcome $(24,32)$ :

"She ha(s) fantastic knowledge ... to help me... She really understands [how] to operate with sick people. She understands me, my sickness and understand(s) my problem." (24) (p. 33). A person-centred relationship was described as a process of joint engagement and collaboration between the participant and the rehabilitation personnel. This included good communication regarding planning and implementation of the rehabilitation $(24,30)$, which was motivating (24). When shortcomings in treatment and communication occurred, experiences of being neglected or treated disrespectfully arose $(25,30)$.

Impersonal and scant information on the course of rehabilitation and future possibilities were experienced as an obstacle in the rehabilitation process. Participants described a lack of individually tailored information as an obstacle to rehabilitation at all phases $(23,29,31)$. They had expected information about their individual condition, future possibilities and long-term consequences, but they mostly received standardized information $(29,31)$. This was experienced as stressful and as an obstacle for reintegration $(23,31)$. In addition, the limited information about rehabilitation options made it difficult for the participants to advocate for their needs $(23,29,31)$. It was often up to the participants to ask for information:

"I asked a lot of questions. I delved. I persisted. I argued. I often got my way, but that's through a lot of persistence and a lot of battling red tape and administration" (23) (p. 443).
The involvement of close persons was crucial for the rehabilitation process. Engagement and support from relatives, friends and colleagues was described as important for the rehabilitation process $(23,25,27-29$, $31,32)$. Emotional support from close persons was important throughout all phases $(25,27-29,31,32)$. Practical support from close persons in activities of daily life and in contacts with authorities was invaluable $(25,27-29,31,32)$. The role of close persons became even more important when the expected services did not function as expected:

"My husband has supported me all along, and I have my sisters who have kept up with the rehabilitation services in our municipality. Not all people have a social network like mine, and if you also have had brain injury, it is difficult to find out where to go. That's probably one of the greatest obstacles" (31) (p. 930).

The participants' experiences show how close persons often take on a burden, to some extent related to limited access to coordinated rehabilitation $(23,25,27-29,31$, $32)$. This burden often became difficult to handle (23, $25,27,29,31,32)$, and returning home was stressful and difficult for the whole family. Tasks and roles needed to change, and the family needed support to manage their changed life situation together $(23,25$, 27-29, 31, 32). The participants felt that the rehabilitation should include close persons through all phases.

\section{Confidence in the findings}

The confidence of the evidence, in each subcategory, was, in most cases, rated as low or moderate (Table III), and the overall considerations for the 4 domains in GRADE-CERQqual were as follows:

- There was a low risk for findings being flawed by methodological limitations, although many studies had insufficient information about the reflexivity of the researchers.

- The synthesis method chosen for the QES included steps to ensure coherence.

- Data adequacy was problematic for all subcategories as the numbers of studies and participants were low.

- Relevance was partially affected for 1 subcategory in which a single study contributed the most information, and this study included a large proportion of persons with other types of acquired brain injury.

\section{DISCUSSION}

This review synthesized the evidence from qualitative studies of the experiences of the rehabilitation process after TBI. The findings show that the participants with TBI experienced limited access to multi-professional team-based brain injury rehabilitation after hospita- 
lization and that the rehabilitation was insufficiently individually tailored and coordinated. Many felt that the services came at the wrong time, had the wrong content, or were not offered. This meant that the participants experienced that they struggled on their own with adapting their daily life, often several years after their injury. The findings from the studies included in the QES reported that participants felt that the rehabilitation would result in better outcomes if they had received the right support at the right time. Thus, the review indicates the importance of enhancing person-centred content as well as access to coordinated team-based rehabilitation over time. This is also in line with current recommendations of person-centred team-based rehabilitation after TBI $(7,8)$. Similar to an earlier review (15), the QES confirmed the need for support in adapting activities of daily life in recreating a meaningful life and a new positive view of the self in the late phases after TBI. As rehabilitation after TBI commonly focuses on recovering, i.e. restoring functions $(3,7$, 33 ), this review indicates a need for shifting focus in the late phase to organize rehabilitation programmes enhancing peoples' skills in self-management in daily life (34). The findings reported across the retrieved studies indicates that improved support for a longer time than offered to the participants is important to meet their needs and enhance their skills to manage daily activities and process changes in life during the adaptation process.

The lack of coordinated team-based rehabilitation after hospitalization could lead to haphazard rehabilitation that largely depended on whether the injured persons themselves, or their close persons, knew their options and requested rehabilitation. This can be seen as problematic from an equality perspective and, in accordance with other literature $(9,10,35)$, stresses the need for improved information, participation and coordinated team-based rehabilitation throughout recovery. Case management, which was reflected upon by a few participants in the QES, has been suggested as a potential resource to improve the coordination of services, even if the scientific evidence for the method needs further evaluation (36). However, this demands that there are rehabilitation services and other forms of services available to coordinate. As the participants did not perceive that the rehabilitation was individually tailored and that they lacked information, this impacted their relationships with professionals and their participation in the rehabilitation. Consequently, many elements of importance for person-centred care (37) were not met. By acknowledging preferences and needs, the relationship between patients and professionals can become more transparent, and continuity of rehabilitation is better supported.
The findings show, in accordance with previous research (10), that transition from hospital is a vulnerable phase. One explanation may be that planning at the hospital lacked opportunities to fully anticipate long-term needs arising in daily life after transition. This suggests that team-based rehabilitation should be developed to better identify needs that arise after the transition. Another vulnerable phase arose when the rehabilitation efforts in the late phase ceased, and people with TBI were required to continue the recovery process on their own. This process can extend many years after formal rehabilitation has ceased $(15,16)$. Similar to other reviews $(15,38)$, the QES confirmed that close persons were important and provided both emotional and practical support during this time In addition, the importance of involving close persons in rehabilitation after TBI was confirmed. However, as the QES was limited to the injured persons' experiences, reviews are needed of close persons' perspectives to better inform about their needs.

The QES followed international guidelines (18) to ensure a transparent and systematic process. To ensure a high-quality synthesis, the researchers had different educational backgrounds and research experiences, integrating various perspectives. The process included continuously going backwards and forwards and questioning the evolving findings (19). Confidence regarding the evidence in the findings was downgraded according to GRADE-CERQual, mainly because data were based on few studies with few participants. Therefore, confidence regarding the subcategories ranged between very low and moderate. In addition, almost all participants in the dataset were of working age, which affects the transferability to older persons with TBI. This is surprising, as many of those who sustain a TBI are older persons (39). Women were in the minority (38\%), and potential differences and similarities related to sex were not a focus. Another aspect that can affect transferability is that experiences may vary in relation to the person's need for rehabilitation, which depends on the severity of the disability and life context. This indicates a need for qualitative research with a purposive selection of participants with respect to the severity, sex and age to enhance confidence in the findings. Moreover, few of the participants in the studies had experienced team-based rehabilitation as access to rehabilitation after discharge from hospital was limited. Further research is therefore needed on the content and significance of rehabilitation, especially in the later phase.

In conclusion, this QES shows that those with TBI undergo a demanding rehabilitation process that requires multi-professional team-based rehabilitation over a longer time than is usually offered. The findings 
indicate a need to improve access to coordinated teambased rehabilitation in the long term and enhance the person-centeredness of services to address the complex needs of persons with TBI. The findings had low to moderate levels of confidence of evidence that largely can be explained by the shortage of research exploring the experiences of people receiving team-based rehabilitation after TBI.

\section{ACKNOWLEDGEMENTS}

The authors are grateful to Ann Kristine Jonsson for the literature search, Karin Wilbe-Ramsay and Naama Kenan Modén for the initial selection of abstracts, Elisabeth Gustavsson for administrative support, SBU, and the librarians at Dalarna University and Örebro University for support with the updated literature search. This study was financed by SBU.

The authors have no conflicts of interest to declare.

\section{REFERENCES}

1. Roozenbeek B, Maas AI, Menon DK. Changing patterns in the epidemiology of traumatic brain injury. Nat Rev Neurol 2013; 9: 231-236.

2. Tagliaferri F, Compagnone C, Korsic M, Servadei F, Kraus J. A systematic review of brain injury epidemiology in Europe. Acta Neurochi 2006; 148: 255-268.

3. Eapen BC, Allred DB, O'Rourke J, Cifu DX, editors. Rehabilitation of moderate-to-severe traumatic brain injury. Semin Neurol 2015; 35: e1-e13.

4. Styrke J, Stålnacke B-M, Sojka P, Björnstig U. Traumatic brain injuries in a well-defined population: epidemiological aspects and severity. J Neurotrauma 2007; 24: 1425-1436.

5. Fadyl JK, Theadom A, Channon A, McPherson KM. Recovery and adaptation after traumatic brain injury in New Zealand: longitudinal qualitative findings over the first two years. Neuropsych Rehabil 2019; 29: 1095-1112.

6. Stocchetti N, Zanier ER. Chronic impact of traumatic brain injury on outcome and quality of life: a narrative review. Crit Care 2016; 20: 148.

7. Wilson BA. Brain injury: recovery and rehabilitation. Cogn Sci $2010 ; 1: 108-118$.

8. Lexell J. Rehabilitation of traumatic brain injuries in Sweden. J Head Trauma Rehabil 2007; 22: 229-233.

9. Cnossen MC, Lingsma HF, Tenovuo O, Maas AI, Menon D, Steyerberg EW, et al. Rehabilitation after traumatic brain injury: a survey in 70 European neurotrauma centres participating in the CENTER-TBI study. J Rehabil Med 2017; 49: 395-401.

10. Tverdal CB, Howe EI, Røe C, Helseth E, Lu J, Tenovuo O, et al. Traumatic brain injury: Patient experience and satisfaction with discharge from trauma hospital. J Rehabil Med 2018; 50: 505-513.

11. Neumann V, Gutenbrunner C, Fialka-Moser V, Christodoulou N, Varela E, Giustini A, et al. Interdisciplinary team working in physical and rehabilitation medicine. J Rehabil Med 2010; 42: 4-8.

12. Kumar KS, Samuelkamaleshkumar S, Viswanathan A, Macaden AS. Cognitive rehabilitation for adults with traumatic brain injury to improve occupational outcomes. Cochrane Database Syst Rev 2017; 6.

13. Turner-Stokes L, Pick A, Nair A, Disler PB, Wade DT. Multidisciplinary rehabilitation for acquired brain injury in adults of working age. Cochrane Database Syst Rev. 2015; 12.

14. Möller MC, Lexell J, Ramsay KW. Effectiveness of spe- cialized rehabilitation after mild traumatic brain injury: a systematic review and meta-analysis. J Rehabil Med 2021; 53: jrm00149.

15. Levack WM, Kayes NM, Fadyl JK. Experience of recovery and outcome following traumatic brain injury: a metasynthesis of qualitative research. Disabil Rehabil 2010; 32: 986-999.

16. D'Cruz K, Douglas J, Serry T. Personal narrative approaches in rehabilitation following traumatic brain injury: a synthesis of qualitative research. Neuropsychol Rehabil 2019; 29: 985-1004.

17. The Swedish Agency for Health Technology Assessment and Assessment of Social Services (SBU). Rehabilitering för vuxna med traumatisk hjärnskada: En systematisk översikt och utvärdering av medicinska, ekonomiska, sociala och etiska aspekter [In english: rehabiliation for adults with acquired brain injury: a systematic review and evaluation of medical, economic, social and ethical aspects.] Stockholm: SBU; 2019.

18. Tong A, Flemming K, McInnes E, Oliver S, Craig J. Enhancing transparency in reporting the synthesis of qualitative research: ENTREQ. BMC Med Res Method 2012; 12: 181.

19. Finfgeld-Connett D. Use of content analysis to conduct knowledge-building and theory-generating qualitative systematic reviews. Qual Res 2013; 14: 341-352.

20. Lewin S, Booth A, Glenton C, Munthe-Kaas H, Rashidian $A$, Wainwright $M$, et al. Applying GRADE-CERQual to qualitative evidence synthesis findings: introduction to the series. Impl Sci 2018; 13: 2.

21. Lewin S, Glenton C, Munthe-Kaas H, Carlsen B, Colvin $\mathrm{CJ}$, Gulmezoglu M, et al. Using qualitative evidence in decision making for health and social interventions: an approach to assess confidence in findings from qualitative evidence syntheses (GRADE-CERQual). PLoS Med 2015; 12: e1001895.

22. Lewin S, Bohren M, Rashidian A, Munthe-Kaas H, Glenton C, Colvin CJ, et al. Applying GRADE-CERQual to qualitative evidence synthesis findings - paper 2: how to make an overall CERQual assessment of confidence and create a summary of qualitative findings table. Impl Sci 2018; 13: 10 .

23. Copley A, McAllister L, Wilson L. We finally learnt to demand: consumers' access to rehabilitation following traumatic brain injury. Brain Imp 2013; 14: 436-449.

24. D'Cruz K, Howie L, Lentin P. Client-centred practice: perspectives of persons with a traumatic brain injury. Scand J Occup Ther 2016; 23: 30-38.

25. Fleming J, Sampson J, Cornwell P, Turner B, Griffin J. Brain injury rehabilitation: the lived experience of inpatients and their family caregivers. Scand J Occup Ther 2012; 19: 184-193.

26. O'Callaghan A, McAllister L, Wilson L. Insight vs readiness: factors affecting engagement in therapy from the perspectives of adults with TBI and their significant others. Brain Inj 2012; 26: 1599-1610.

27. Turner B, Fleming J, Cornwell P, Worrall L, Ownsworth $T$, Haines $T$, et al. A qualitative study of the transition from hospital to home for individuals with acquired brain injury and their family caregivers. Brain Inj 2007; 21: 1119-1130.

28. Turner BJ, Fleming J, Ownsworth T, Cornwell P. Perceived service and support needs during transition from hospital to home following acquired brain injury. Disabil Rehabil 2011; 33: 818-829.

29. Mueller C, Wang Y, Brooks A, Morant N, Sullivan P, Raymont V. "Attending to the wound and the person" - patients" experiences and expectations of a newly established traumatic brain injury clinic. Brain Inj 2017; 31: 1863-1870.

30. Abrahamson V, Jensen J, Springett K, Sakel M. Experiences of patients with traumatic brain injury and their carers during transition from in-patient rehabilitation to the community: a qualitative study. Disabil Rehabil 2017; 39: $1683-1694$. 
31. Graff HJ, Christensen U, Poulsen I, Egerod I. Patient perspectives on navigating the field of traumatic brain injury rehabilitation: a qualitative thematic analysis. DisabiL Rehabil 2018; 40: 926-934.

32. Månsson Lexell $E$, Alkhed $A-K$, Olsson $K$. The group rehabilitation helped me adjust to a new life: Experiences shared by persons with an acquired brain injury. Brain Inj 2013; 27: 529-537.

33. Maas AI, Stocchetti N, Bullock R. Moderate and severe traumatic brain injury in adults. Lancet Neurol 2008; 7: 728-741.

34. Lorig KR, Holman HR. Self-management education: history, definition, outcomes, and mechanisms. Ann Behav Med 2003; 26: 1-7.

35. Plant SE, Tyson SF, Kirk S, Parsons J. What are the barriers and facilitators to goal-setting during rehabilitation for stroke and other acquired brain injuries? A systematic review and meta-synthesis. Clin Rehabil 2016; 30: 921-930.

36. Clark-Wilson J, Holloway M. Life care planning and longterm care for individuals with brain injury in the UK. NeuroRehabil 2015; 36: 289-300.

37. Ekman I, Swedberg K, Taft C, Lindseth A, Norberg A, Brink $E$, et al. Person-centered care - ready for prime time. Euro J Cardiovasc Nurs 2011; 10: 248-251.

38. Verhaeghe S, Defloor T, Grypdonck M. Stress and coping among families of patients with traumatic brain injury: a review of the literature. J Clin Nurs 2005; 14: 1004-1012.

39. Peters ME, Gardner RC. Traumatic brain injury in older adults: do we need a different approach? Concussion 2018; 3: CNC56. 
p. 10 of 12 M. Larsson-Lund et al.

Appendix 1. Example of search strategy. PubMed via National Library of Medicine, 24 March 2021

Number Search terms

Items found

Population: traumatic brain injury

1. "Brain Hemorrhage, Traumatic"[Mesh] OR "Brain Concussion"[Mesh] OR "Brain Injuries/rehabilitation "[Mesh] OR "Brain Injuries, Traumatic"[Mesh] OR "Brain Injury, Chronic"[Mesh] OR "Craniocerebral Trauma/rehabilitation"[Mesh] OR "Contrecoup Injury"[Mesh] OR "Craniocerebral Trauma"[Mesh: noexp] OR "Head Injuries, Penetrating"[Mesh] OR "Intracranial Hemorrhage, Traumatic"[Mesh] OR "Post-Concussion Syndrome"[Mesh] OR "Subarachnoid Hemorrhage, Traumatic"[Mesh]

2. (acquired brain injur*[tiab] OR brain concussion[tiab] OR brain contusion*[tiab] OR brain damage[tiab] OR brain injured[tiab] OR brain injur*[tiab] OR brain rehabilitation[tiab] OR brain trauma[tiab] OR brainstem injury[tiab] OR cerebral contusion*[tiab] OR cerebral damage[tiab] OR cerebral injur*[tiab] OR cerebral trauma*[tiab] OR concussi*[tiab] OR cranial injury[tiab] OR cranial injuries[tiab] OR cranial trauma[tiab] OR craniocerebral trauma[tiab] OR forehead trauma[tiab] OR head injur*[tiab] OR head trauma[tiab] OR mTBI[tiab] OR post-concussi*[tiab] OR postconcussi*[tiab] OR severe brain contusion[tiab] OR severe brain injuries[tiab] OR severe brain injury[tiab] OR severe TBI[tiab] OR TBI rehabilitation[tiab] OR TBI Model Systems[tiab] OR traumatic encephalopath*[tiab] OR traumatic brain[tiab] OR traumatic cerebral*[tiab] OR traumatic head[tiab] OR traumatic injur*[tiab]) NOT medline[sb]

3. 1 OR 2

Perspective: patients experiences and attitudes

4. "Adaptation, Psychological"[Mesh] OR "Attitude"[Mesh:NoExp] OR "Attitude to Health"[Mesh:NoExp] OR "Communication"[Mesh] OR "Communication Barriers"[Mesh] OR "Expressed Emotion"[Mesh] OR "Health Communication"[Mesh] OR "Interpersonal Relations"[Mesh] OR "Nurse-Patient Relations"[Mesh] OR "Patient Acceptance of Health Care"[Mesh] OR "Patient Participation"[Mesh] OR "Patient Satisfaction"[Mesh] OR "Personal Satisfaction"[Mesh] OR "Physician-Patient Relations"[Mesh] OR "Professional-Patient Relations"[Mesh:NoExp] OR "Quality of Life"[Mesh] OR "Resilience, Psychological"[Mesh]

5. (attitude*[tiab] OR belief*[tiab] OR embodied[tiab] OR emotional[tiab] OR experience*[tiab] OR health care consultation[tiab] OR interpretation[tiab] OR meaning[tiab] OR nursing encounter*[tiab] OR perception[tiab] OR perspective*[tiab] OR professional consultation[tiab] OR nursing consultation[tiab] OR psychological[tiab] OR relation[tiab] OR resilience[tiab] OR satisfaction[tiab] OR self-report[tiab] OR stigma[tiab] OR trust[tiab] OR value[tiab] OR view[tiab]) NOT medline[sb]

6. 4 OR 5

$7 \quad 3$ AND 6

Study types: qualitative research ${ }^{1}$

8 "Qualitative Research"[Mesh] OR "Grounded Theory"[Mesh] OR "Interviews as Topic"[Mesh] OR "Interview, Psychological"[Mesh] OR "Nursing Research"[Mesh] OR "Health Services Research"[Mesh] OR "Epidemiologic Methods"[Mesh] OR "Personal Narratives as Topic"[Mesh] OR "Anecdotes as Topic"[Mesh] OR "Video Recording"[Mesh] OR "Tape Recording"[Mesh] OR qualitative*[Title/Abstract] OR interview*[Title/Abstract] OR focus group*[Title/Abstract] OR phenomeno*[Title/Abstract] OR phenomenograph*[Title/Abstract] OR ethnolog*[Title/Abstract] OR ethnographic*[Title/Abstract] OR hermeneutic*[Title/Abstract] OR grounded theory[Title/Abstract] OR observation[Title/Abstract] OR lived experience*[Title/Abstract] OR narrat*[Title/Abstract] OR field work*[Title/Abstract] OR field stud*[Title/Abstract] OR mixed method*[Title/Abstract] OR content analysis[Title/Abstract] OR discourse analysis[Title/Abstract] OR poststructur*[Title/Abstract] OR mixed method*[Title/Abstract] OR purposive sample*[Title/Abstract] OR social systems theor*[Title/ Abstract] OR thematic analys*[Title/Abstract] OR theoretical sample*[Title/Abstract]

Combined sets/Limits: publication year, language

9 7 AND 8 /Filters activated: Publication date from 2020/01/01, Danish, English, Norwegian, Swedish

${ }^{1}$ No validated or evaluated filter used.

The search result, usually found at the end of the documentation, forms the list of abstracts.

$[\mathrm{MeSH}]=$ Term from the Medline controlled vocabulary, including terms found below this term in the MeSH hierarchy

[MeSH:NoExp]=Does not include terms found below this term in the MeSH hierarchy

$[\mathrm{MAJR}]=$ MeSH Major Topic

$[\mathrm{TIAB}]=$ Title or abstract

$[\mathrm{TI}]=$ Title

$[\mathrm{AU}]=$ Author

$[\mathrm{OT}]=$ Other term

[TW] $=$ Text Word

Systematic $[\mathrm{SB}]=$ Filter for retrieving systematic reviews

*Truncation 


\section{Appendix 2. Assessment of methodological limitations, studies with qualitative methodology}

Author:

Reviewer:

Questions
Year:

Included in the synthesis:

\section{Yes No Unclear}

1. Was there an agreement between philosophy/theoretical underpinnings and design and conduct of the study?

What theory or philosophical approach did the authors use?

Can a lack of agreement between theory/philosophical approach and study design affect the findings?

$\square \quad \square \quad \square$

Comments:

\section{Context}

What was the context?

Support question for assessing the choice of context:

Is the context reasonable for investigating the phenomenon of interest?

Can the selected context affect the findings?

Comments:

\section{Participants}

How was the selection made?

Support questions for assessing deficiencies in the selection procedure:

Is the selection appropriate for the phenomenon in question?

Is the recruitment method appropriately selected and implemented?

Are there deficiencies in the selection that can affect the findings?

Comments:

4. Data collection

What methods were used for data collection?

Support questions for assessing deficiencies in data collection:

Is the form of data collection appropriate to clarify the phenomenon in question?

Are there flaws in data collection that can affect the findings?

Comments:

5. Analysis

What methods were used for analysis?

Support questions for assessing deficiencies in the analysis phase:

Is the chosen method of analysis suitable and carried out in an appropriate way?

Were the researchers reflexive in interpreting data?

Were the interpretations validated?

Are there flaws in the analysis that can affect the findings?

Comments:

\section{Researcher}

How many researches were involved in the study and what were their field of competence?

Support questions for assessing problems with related to the researchers:

Did the researchers have any relation to the study participants that may influence data collection?

Had the researchers handled their pre-understanding in an acceptable way?

Were the researchers independent of financial or other conditions that could influence the analysis?

Are there deficiencies that can affect the findings?

Comments:

Overall risk that results are flawed by methodological limitations:

Insignificant or low $\square$

Moderate $\square$

High, the study is not included in the synthesis

Comments:

\section{Questions used for assessment of CERQual (only applied on included studies)}

\section{Coherence}

Support questions for assessing coherence:

Were the main body of the data used in the analysis?

Were conflicting data handled appropriately?

Did the data support the findings?

Overall, are there weaknesses that could lead to a lack of coherence in the synthesised scientific evidence?

Comments:

\section{Adequate data}

\section{Support questions for assessing adequacy of data:}

Were the number of participants in the study enough for the results to be representative (e.g., whether saturation reached)?

Is the range of participants sufficient to cover all perspectives of the phenomenon in question?

Has the form of data-collection been sufficient to allow rich and necessary data?

Overall, are there weaknesses that may lead to a lack of coherence in the overall scientific evidence

Comments:

$\square \quad \square \quad \square$

$\square \quad \square \quad \square$ 
Appendix 3. Excluded studies.

Article

Aitken L, Chaboyer W, Jeffrey C, Martin B, Whitty J, Schuetz M, et al. Indicators of injury recovery identified by patients, family members and clinicians. Injury 2016; 47: 2655-2663.

Braaf, S., Ameratunga S, Christie N, Teague W, Ponsford J, Cameron PA, et al. Care coordination experiences of people with traumatic brain injury and their family members in the 4-years after injury: a qualitative analysis. Brain Inj 2019; 33: 574-583.

Dams-O'Connor K, Landau A, De Lore JS, Hoffman J. Access, barriers, and health care quality after brain injury: Insiders' perspectives. Arch Phys Med Rehab 2016; 97: e129.

Dams-O'Connor K, Landau A, Hoffman J, St De Lore J. Patient perspectives on quality and access to healthcare after brain injury. Brain Inj 2018; 32: 431-441.

Darragh AR, Sample PL, Krieger SR. "Tears in my eyes 'cause somebody finally understood": client perceptions of practitioners following brain injury. Am J Occup Ther 2001; 55: 191-199.

Doig E, Fleming J, Cornwell PL, Kuipers P. Qualitative exploration of a client-centered, goal-directed approach to communitybased occupational therapy for adults with traumatic brain injury. Am J Occup Ther 2009; 63: 559-568.

Eliacin J, Fortney S, Rattray NA, Kean J. Access to health services for moderate to severe TBI in Indiana: patient and caregiver perspectives. Brain Inj 2018; 32: 1510-1517.

Fadyl JK, Theadom A, Channon A, McPherson KM. Recovery and adaptation after traumatic brain injury in New Zealand: longitudinal qualitative findings over the first two years, Neuropsych Rehabil 2019; 29: 1095-1112

Foster M, Legg M, Hummell E, Burridge L, Laurie K. Right people, right time? A qualitative study of service access experiences of adults with acquired brain injury following discharge from inpatient rehabilitation. Brain Impair 2021; 22: 92-107.

Gill IJ, Wall G, Simpson J. Clients' perspectives of rehabilitation in one acquired brain injury residential rehabilitation unit: a thematic analysis. Brain Inj 2012; 26: 909-920.

Gravell R, Brumfit S, Body R. Hope and engagement following acquired brain injury: a qualitative study. Brain Inj 2017; 31: 721-722.

Haag HL, Caringal M, Sokoloff S, Kontos P, Yoshida K, Colantonio A. Being a woman with acquired brain injury: challenges and implications for practice. Arch Phys Med Rehab 2016; 97: S64-70.

Harrison AL, Hunter EG, Thomas H, Bordy P, Stokes E, Kitzman P. Living with traumatic brain injury in a rural setting: supports and barriers across the continuum of care. Disabil Rehabil 2017; 20: 2071-2080.

Hoogerdijk B, Runge $U$, Haugboelle $J$. The adaptation process after traumatic brain injury an individual and ongoing occupational Not team-based rehabilitation struggle to gain a new identity. Scand J Occup Ther 2011; 18:122-132.

Hooson JM, Coetzer R, Stew G, Moore A. Patients' experience of return to work rehabilitation following traumatic brain injury: a phenomenological study. Neuropsych Rehabil 2013; 23: 19-44.

Jumisko E, Lexell J, Soderberg S. The experiences of treatment from other people as narrated by people with moderate or severe traumatic brain injury and their close relatives. Disabil Rehabil 2007; 29: 1535-1543.

Knox L, Douglas J, Bigby C. "There's a lot of things that I just know I can't influence": The experiences of adults with severe TBI and their partners in making decisions about life after injury. Brain Impair 2013; 14: 169-170.

Knox L, Douglas JM, Bigby C. "I've never been a yes person": decision-making participation and self-conceptualization after severe traumatic brain injury. Disabil Rehabil 2017; 39: 2250-2260.

Kuipers K, Cox R, Doherty D, Grudzinskas K. The process of developing a non-medical (advanced allied health) botulinum toxin A prescribing and injecting model of care in a public rehabilitation setting. Aust Health Rev 2013; 37: 624-631.

Lannin N, Roberts K, D'Cruz K, Morarty J, Unsworth C. Who holds the 'Power' during goal-setting? A qualitative study exploring patient perceptions. Int J Stroke 2015; 10: 68.

Larsson Lund M, Lovgren-Engstrom AL, Lexell J. Using everyday technology to compensate for difficulties in task performance in daily life: experiences in persons with acquired brain injury and their significant others. Disabil Rehabil Assist Technol 2011; 6: 402-411.

Lefebvre $\mathrm{H}$, Levert MJ. Breaking the news of traumatic brain injury and incapacities. Brain Inj 2006; 20: 711-718.

Lefebvre H, Pelchat D, Swaine B, Gelinas I, Levert MJ. The experiences of individuals with a traumatic brain injury, families, physicians and health professionals regarding care provided throughout the continuum. Brain Inj 2005; 19: 585-597.

Lefkovist AM, Hicks AJ, Downing M, Ponsford J. Surviving the "silent epidemic": a qualitative exploration of the long-term journey after traumatic brain injury. Neuropsych Rehabil 2020: E-pub 2020/07/15.

Leith $\mathrm{KH}$, Phillips L, Sample PL. Exploring the service needs and experiences of persons with TBI and their families: the South Carolina experience. Brain Inj 2004; 18):1191-1208.

Lindstad M $\varnothing$, Andelic N, Sveen U. Living with cognitive challenges after traumatic brain injury. Experiences of developing coping strategies-A qualitative study. Brain Inj 2016; 30: 584.

Lundqvist A, Samuelsson K. Return to work after acquired brain injury: a patient perspective. Brain Inj 2012; 26 : $1574-1585$. Morris PG, Prior L, Deb S, Lewis G, Mayle W, Burrow CE, et al. Patients' views on outcome following head injury: a qualitative study. BMC Fam Pract 2005; 6: 30-36.

Nalder E, Fleming J, Cornwell P, Shields C, Foster M. Reflections on life: experiences of individuals with brain injury during the transition from hospital to home. Brain Inj 2013; 27: 1294-1303.

O'Callaghan A, McNamara B, Cocks E. 'What am I supposed to do? Cartwheels down the passageway?' Perspectives on the rehabilitation journey from people with ABI. Brain Inj 2014; 28: 577-578.

O'Callaghan AM, McAllister L, Wilson L. Experiences of care reported by adults with traumatic brain injury. Int J Speech-Lang Pa 2010; 12: 107-123.

Patterson F, Fleming J, Doig E. Clinician perceptions about inpatient occupational therapy groups in traumatic brain injury rehabilitation. Brain Inj 2017; 31:1077-1087.

Soeker MS, Van Rensburg V, Travill A. Are rehabilitation programmes enabling clients to return to work? Return to work perspectives of individuals with mild to moderate brain injury in South Africa. Work 2012; 43: 171-182.

Stergiou-Kita M, Mansfield E, Sokoloff S, Colantonio A. Gender influences on return to work after mild traumatic brain injury. Arch Phys Med Rehab 2016; 97: S40-45.

Talbot LR, Levesque A, Trottier J. Process of implementing collaborative care and its impacts on the provision of care and rehabilitation services to patients with a moderate or severe traumatic brain injury. J Multidiscip Healthc 2014; 7: 313-320.

van Velzen JM, van Bennekom CAM, van Dormolen M, Sluiter JK, Frings-Dresen MHW. Factors influencing return to work experienced by people with acquired brain injury: a qualitative research study. Disabil Rehabil 2011; 33: $2237-2246$.

White BP, Brinkman A, Kresge BP, Couture L. Quality of life, stress perception, and quality of social networks in persons living with brain injury: an exploration of the effectiveness of a community-based program. OJOT 2018; 6: 1-14.

Ylvisaker M, McPherson K, Kayes N, Pellett E. Metaphoric identity mapping: facilitating goal setting and engagement in rehabilitation after traumatic brain injury. Neuropsych Rehabil 2008; 18: 713-741.
Reason for exclusion

Not team-based rehabilitation

Not team-based rehabilitation

Not peer-reviewed article

Methodological limitations

Methodological limitations

Not team-based rehabilitation

Not team-based rehabilitation

Not team-based rehabilitation

Too low proportion TBI

Methodological limitations

Not peer-reviewed article

Not team-based rehabilitation

Methodological limitations

Methodological limitations

Not team-based rehabilitation

Not peer-reviewed article

Not team-based rehabilitation

Not team-based rehabilitation

Not peer-reviewed article

Not team-based rehabilitation

Methodological limitations Methodological limitations

Methodological limitations

Methodological limitations

Not peer-reviewed article

Too low proportion TBI

Not team-based rehabilitation

Not team-based rehabilitation

Not peer-reviewed article

Not a qualitative study

Not client perspective

Methodological limitations

Methodological limitations

Too low proportion TBI

Not team-based rehabilitation

Methodological limitations
Methodological limitations

TBI: traumatic brain injury. 